\title{
A recusa do esquecimento em A casa-comboio
}

\author{
SHEILA KHAN \\ Pós-doutoranda nas universidades de Manchester (Departamento de Estudos Espanbóis e Portugueses) \\ e de Coimbra (Centro de Estudos Sociais)
}

\begin{abstract}
RESUMO: PARTINDO DE UMA REFLEXÃO SOCIOLÓGICA DO ROMANCE DE RAQUEL OCHOA, A CASA-COMBOIO E À LUZ DE UMA SOCIOLOGIA "PÓS-COLONIAL" DAS AUSÊNCIAS, O PRESENTE ENSAIO TEM POR OBJECTIVO ANALISAR, POR UM LADO, AS CONTINUIDADES MNEMÓNICAS DO IMPÉRIO PORTUGUÊS NAS NARRATIVAS INDO-PORTUGUESAS E, POR OUTRO LADO, A FRÁGIL CONSCIÊNCIA E RECONHECIMENTO DESSAS NARRATIVAS DE IDENTIDADE NO TECIDO DA PÓS-COLONIALIDADE PORTUGUESA.
\end{abstract}

ABSTRACT: TAKING AS ITS POINT OF DEPARTURE A SOCIOLOGICAL READING OF RAQUEL OCHOA'S NOVEL A CASA-COMBOIO, AND ALSO TAKING INTO ACCOUNT THE OBSERVATIONS MADE BY THE SOCIOLOGY OF "POSTCOLONIAL" ABSENCES, THIS ESSAY AIMS TO ANALYSE, ON THE ONE HAND, THE MNEMONIC CONTINUITIES OF THE PORTUGUESE EMPIRE WITHIN INDO-PORTUGUESE NARRATIVES AND, ON THE OTHER HAND, TO MEASURE THE AWARENESS AND RECOGNITION OF THESE IDENTITYBASED NARRATIVES WITHIN THE FABRIC OF PORTUGUESE POSTCOLONIALITY.

PALAVRAS-CHAVE: COLONIALISMO, PÓS-COLONIALISMO, IDENTIDADE, MEMÓRIA E NARRATIVA.

KEYWORDS: COLONIALISM, POSTCOLONIALISM, IDENTITY, MEMORY AND NARRATIVE. 
Mas o que eu sei é que o homem deve construir o seu reino, achar o seu lugar

na verdade da vida, da terra, dos astros,

o que sei é que a morte não deve ter razão contra a vida

nem os deuses voltar a tê-la contra os homens, o que sei

é que esta evidência inicial nos espera no fim de todas as conquistas

para que o ciclo se feche - o ciclo, a viagem mais perfeita.

Vergílio Ferreira (1980, p. 247)

\section{Introdução}

rêmio Literário Revelação Agustina Bessa-Luís em 2009, o mais recente livro de Raquel Ochoa, A casa-comboio, história de uma família indo-portuguesa, a família Carcomo, apresenta-se como uma abordagem etnográfica, embora de timbre literário, que nos permite identificar os silêncios, os enclaves identitários do pós-colonialismo de língua portuguesa, no que toca as narrativas de vida e de identidade dos chamados indo-portugueses. Este ensaio ${ }^{1}$ resulta de uma reflexão não exaustivamente preocupada com os componentes comuns e intrínsecos a um trabalho de análise literária. Pelo contrário, este trabalho surge como uma tarefa de análise sociológica e etnográfica que procura entrelaçar aspectos da literatura (sobretudo das literaturas de língua portuguesa) com o questionamento e inquirição do real (MARTINS, 2005, p. 81) da sociedade contemporânea pós-colonial portuguesa, partindo então da premissa de que o manancial literário pode ser chamado para uma área de debate social, cultural e histórico no intuito de melhor compreendermos os vazios de outras formas de discurso, sobretudo aqueles que dizem respeito à materialização da subjetivida-

1. Este artigo é fruto de uma comunicação apresentada no Colóquio internacional, Pena-insularidades: escrever o oriente e o ocidente em português, que teve lugar na Universidade de Bristol em abril de 2011. Gostaria de, no âmbito desta breve informação, agradecer os comentários enriquecedores e bastante pertinentes de Hélder Garmes, Paul Melo e Castro e de Egídia Souto, que se revelaram, posteriormente, no espaço e tempo de sedimentação deste trabalho, como conselhos para uma atenção mais analítica de determinados aspectos da obra em questão e para outros paralelos não menos importantes. Realço também a importância da comunicação apresentada, nesse evento, por Everton M. Machado, "Uma velha casa em ruínas: identidade e representação na obra dos goeses Vimala Devi, Orlando da Costa e Leopoldo Rocha", que muito me auxiliou quando transformei minha comunicação no presente artigo. 
de do sujeito histórico na atualidade. Fazendo da literatura um instrumento de compreensão do real, este ensaio serve para criticamente entender não apenas a pós-colonialidade portuguesa e a sua retórica mítica acerca do multiculturalismo e da política de integração bem-sucedida dos sujeitos oriundos das ex-colônias portuguesas, orientais e africanas, mas evidenciar as contradições que afloram no trato com um passado que promoveu a descolonização dos territórios, mas não a descolonização das mentes, das emoções e dos universos subjetivos. Mais do que uma viagem ao tempo colonial realizada por personagens que já vivem o momento pós-colonial (MALHEIROS, 2010, p. 165), esse romance nos propõe um grande empasse: querer saber e reconhecer o passado ou simplesmente esquecê-lo. É esse um dos grandes desafios que atormenta parte da literatura de língua portuguesa na pós-colonialidade. Na verdade, poder-se-ia já nestas primeiras linhas observar o compromisso literário de Raquel Ochoa com a história indo-portuguesa e seu mundo e tempo coevos, pois logo no intróito ao seu livro, escreve-nos:

(...) este livro é uma homenagem a uma espécie de portugueses a que devemos tributo. Honorato, Rudolfo e Baltazar, nomes fictícios de pessoas verdadeiras, encarnam a valentia dos homens comuns, dos que não se deixaram despedaçar pelo destino (...). Esta é a história da partida que agora regressa, pois a Índia passeia pelas ruas de Lisboa, apanha os mesmos transportes que nós e senta-se ao nosso lado no cinema. (OCHOA, 2010, p. 7).

O relevo social desta "casa-comboio" mostra-nos bem os défices embutidos em todos aqueles que um dia acreditaram ser parte indelével de um império que no seu tempo, supostamente, se pensara incólume e resistente às intempéries de tudo e de todos. A «casa-comboio"» pode ser tomada como a alegoria de um colonizador que, mesmo dono de um vasto império, também se compôs de fissuras e debilidades. Encetemos, então, a viagem.

\section{A modernidade portuguesa no Oriente}

A narração desta "casa-comboio" inicia-se no século XIX com a presença portuguesa nos seus territórios indianos. Trata da vida e do trânsito de perso- 
nagens entre Goa, Damão, Diu, Nagar-Aveli, familiarizando o leitor com os universos e enquadramentos sociais e culturais que sustentaram o colonialismo português nesses territórios. Tal colonialismo entendia-se como elemento gerador de modernidade e se julgava o centro civilizador desses povos, concorrendo com uma outra matriz colonizadora: o colonialismo britânico. Acompanhando as narrativas de vida de Honorato, Rudolfo, Baltazar e, num tempo mais próximo ao momento presente, de Clara - como herdeira desse modo de ser colonizado, cultivado por seus antepassados. Vemos então surgirem situações muitos interessantes, uma vez que se sentem como parte de um grande império, que ultrapassa em muito as fronteiras com as quais convivem e estão habituados a transitar. Aciona-se, assim, um imaginário vasto, amplo, glorioso, que povoa os sonhos daqueles personagens:

Será que nunca vou conhecer Portugal?

Honorato tinha um fascínio solitário, que jamais se expandira para além do seu artesoado de pensamentos. Inexplicavelmente, porque os sonhos são comédias em câmara lenta, sonhava com o Alentejo. As planíces alaranjadas eram o maior refúgio, onde a sua alma lhe confessava o sangue português. Há uns anos até procurara a árvore genealógica da sua família, queria perceber de onde vinha este sonho recorrente. Quanto mais dormia, mais sonhava, mais se sentia lá em vez de cá. (OCHOA, 2010, p. 24).

Essa maneira de estar perto desse lugar idealizado pelo exercício da imaginação é como uma arma astuta do colonialismo português para angariar a cumplicidade dos indianos. Ao outorgar-lhe certa cidadania e certo reconhecimento identitário, vai na verdade despojando-os de um verdadeiro sentido pátrio e territorial, que só poderia existir ligado a suas práticas e espaços concretos de existência, descolando-os, assim, do território real de suas narrativas identitárias (KHAN, 2006, p. 17). Alguns estudos, ainda que apontando para outras abordagens temáticas da literatura portuguesa como, por exemplo, o caso da literatura sobre a emigração/imigração portuguesa na França, mostram-nos pistas relevantes para salientar esse conúbio entre território e identidade. Nesse sentido, torna-se então pertinente, como sublinha Lourdes Martins, que a abordagem deste conceito demonstre que 
o território, juntamente com a língua, bem como a cultura erudita ou popular, a história, a mentalidade e o interesse comum são dimensões dessa identidade pela sua natureza objectiva, mas também os seus «significantes», subjectivamente apreendidos, pela produção simbólica que nela se investe. Portador de sentido e objecto de simbolização intensa, o território é [...] um lugar antropológico, identitário e simultaneamente relacional e histórico. (MARTINS, 2005, p. 82; MUNOZ, 1994)

A pertinência da afirmação acima se evindencia no romance. A exportação da identidade e da cidadania portuguesas para a Índia, assim como fizeram outras nações colonizadoras em várias partes do mundo, gerou uma série de contradições e mesmo paradoxos para aqueles que se viram na contingência de adotar uma pátria que, de fato, não conheciam. A seguinte passagem do romance ilustra a estupefacção de Rudolfo, um dos personagens centrais da diegese:

\section{Pai, Portugal é longe?}

Oh que disparate! Portugal é aqui - respondeu-lhe Honorato.

Sim, eu sei, mas se Portugal é aqui, por que é que Portugal é tão longe? (OCHOA, 2010, p. 77).

O território-pátrio português é importado para Índia por força ideológica. Essa ideologia assegura que todos os indianos que nasceram nas colônias portuguesas são tão portugueses quanto os da metrópole e, portanto, possuem os mesmos direitos e deveres daqueles. Todavia, enquanto o discurso ideológico estatal funciona como força aglutinadora, a prática funciona de forma segregacionista, como observa o narrador onisciente:

Salazar afirmava que os habitantes portugueses dos estados indianos - e estes corroboravam - estavam perfeitamente integrados, dispondo dos mesmos direitos e obrigações de que gozavam os habitantes de Portugal Continental. Contudo, as políticas aplicadas foram aligeiradas nas últimas décadas de colonização. Mesmo que sejam políticas nãoracistas, vamos chamar-lhes assim, os cargos de poder, como os altos cargos administrativos, raramente eram e raramente são partilhados com os goeses, mesmo que estes tivessem estatuto de cidadãos de Portugal. (OCHOA, 2010, p. 180 e 225). 
No século XIX e início do século XX, enquanto não havia fortes movimentos contra o colonialismo, as personagens do livro vivem tais constradições sem que isso lhes cause grande constrangimento. Todavia, a partir da independência da Índia em 1947 e do surgimento de pressões da União Indiana para o fim do colonialismo Português em Goa, tudo começa a mudar. A vitória dos freedom fighters em 1961 fez com que muitos dos goeses cristãos que se consideravam portugueses «retornassem» a Portugal, pátria que, em verdade, lhes era totalmente desconhecida, apenas imaginada. Nesse momento, muitos se questionam: "Mas afinal quem era Portugal?" (OCHOA, 2010, p. 230). A pergunta que se coloca no romance é: após a libertação de Goa, um indo-português deveria permanecer na Índia ou ir para Portugal? A simples questão evidencia a preocupação etnográfica presente na obra, pois, para o indo-português convicto, a experiência de exílio se daria quer fosse para Portugal, quer ficasse em Goa, agora totalmente indiana. Retomando o romance de viagem de Eduardo Agualusa, Um estranho em Goa (2007), o «estranho» em Goa, como tivemos oportunidade de argumentar num outro tempo de reflexão (KHAN, 2011), não era apenas o narrador, mas todos aqueles oriundos do processo colonial português, cuja marca identitária era rejeitada pela Goa indiana. O empasse acerca da identidade hindo-portuguesa no período pós-colonial se constrói de forma exemplar no romance, estabelecendo uma relação ambígua e conflituosa com o passado colonial e uma relação tensa e de estranhamento com a realidade presente.

\section{A geração do imaginário imperial, a geração do silêncio, a geração da diáspora: a pátria-comboio sempre em viagem}

O tempo em que se deu a "descolonização" e o consequente "repatriamento" de parte desses indo-portugueses para Portugal caracterizou-se sobretudo pela dúvida e pela insegurança no plano identitário. De cidadãos de um império que já não existia e que também não se reconheciam na nação indiana que então se consolidava, passaram a se perguntar: "a que país se pertence quando tudo o que se conheceu faz parte de uma cultura importada de outro continente?" (OCHOA, 2010, p. 255). Os indo-portugueses foram a primeira cultura "paralela" que os portugueses inventaram além-oceano e que, passa- 
dos 450 anos, retornaram para casa onde nunca estiveram. "O regresso foi um processo complexo para ambas as partes, tanto para os que esperavam integrar-se, como para os que - mais ou menos abertamente - cumpriam o papel de os integrar" (OCHOA, 2010, p. 267).

Eduardo Lourenço, em seu precioso livro Labirinto da Saudade (2001) escrevera já sobre o grande desconhecimento entre o império da metrópole e o império remoto, esse outro-nosso-desconhecido, do qual se fala mas que não é escutado, sobre o qual se pensa mas que jamais é entendido e reconhecido. Helena Buescu, em Emendar a morte, pactos em literatura (2008), reitera-nos, a partir de uma análise meticulosa do romance de Lobo Antunes, As Naus (1990), essa mesma observação, reforçando, desse modo, a reflexão de Eduardo Lourenço no que concerne a intrínseca disjunção desse império, que não reconhece suas próprias criações, talvez porque elas também não se reconheçam nele, mantendo as partes, contudo, um vínculo indelével.

Helena Buescu, em seu ensaio sobre os retornos, ou regressos desses-outros-semelhantes, esculpe analiticamente o mundo habitado «em dor» daqueles que retornaram. Para muitos desses indo-portugueses, como para outros casos associados ao fim do colonialismo português na África, " "(...) emigrar era irmos para ... para os Estados Unidos!” (OCHOA, 2010, p. 263), como diz Baltazar um dos personagens da «casa-comboio». Ira para Portugal não era imigrar. Todavia, ali encontrariam essa «dor» sem máscaras de que fala Helena Buescu.

Não nos afastando do fio condutor deste ensaio, faz-se necessário, no entanto, salientar que as propostas de investigação recentes concedem-nos pistas sólidas para melhor e seriamente avaliar a questão de uma «orfandade» que enferma a pós-colonialidade portuguesa, na medida em que muitos estudiosos, partindo das preocupações que alguns textos literários apresentam, vêm mostrando uma permanente incapacidade e negligência da historiografia portuguesa de reconhecer, compreender e acolher outras vozes, outras narrativas, outros

2. Vale a pena chamar de atenção para o romance de Aida Gomes, Os pretos pousaflores (2011). Embora a diegese desse romance se encontre concatenada às experiências dos portugueses na África, o denominador comum com o texto literário de Raquel Ochoa, invariavelmente, recai sobre o tópico do desconhecimento histórico entre os portugueses - outros (sejam estes, por exemplo, os chamados retornados, entre outras categorias sociais criadas pela retórica colonial portuguesa) do «ultramar» e os portugueses da metrópole. 
mundos subjetivos que, legitimamente, deveriam ser chamados à escrita da História colonial e pós-colonial portuguesa (FONSECA, 2005, 2010; CARDOSO, 2010; MATA, 2006). Por conseguinte, não será de estranhar a manifestação do desassossego constante nas personagens centrais do romance em análise, assim como se revela interessante a coexistência num mesmo projeto diegético de várias gerações que se cruzando no tempo do colonialismo português, ora como receptores e crédulos de sua retórica colonial (Honorato, Rudolfo e Baltazar), ora como observadores participantes da queda desse império, do desmoronar de uma vida «prodigiosa» (Rudolfo e Baltazar), ou ainda como testemunhos e participantes das diferentes guerras do ultramar (Baltazar), e, finalmente, como sujeitos silenciosos (ou silenciados?) no universo da pós-colonialidade portuguesa (Rudolfo, Baltazar). Desse longo percurso resulta só desilusão, como confessa o ancião da família, Rudolfo Carcomo: "estou desiludido com isto que é Portugal. Não com o sítio em si nem com o passado, mas sim com a concha que isto é... ou se tornou. Cada um vive para si” (OCHOA, 2010, p. 272). Essa mesma desilusão será a força motora que esses indo-portugueses encontrarão para guardar as suas memórias, as suas nostalgias e encarar esse Portugal que não lê muito bem os seus-outros como a si mesmo e, desse modo, prosseguir com as suas vidas, pois o desafio "passara a ser aqui e ainda havia uma vida inteira pela frente, casas para construir ou pagar, filhos para criar, empregos para manter" (OCHOA, 2010, p. 289).

Se esse silêncio é erigido pela sociedade portuguesa contemporânea, também é compartilhado por aqueles que seriam as vítimas desse mesmo silêncio, já que estes preferem não trazer à tona sua problemática situação identitária em nome da sobrevivência, da urgência de restituir às suas vidas um sentido de continuidade e de existência familiar, de estabilidade e de elaboração de perspectivas futuras. No entanto, os muros de mutismo que as gerações anteriores suportaram vão sendo, paulatina e atentamente, derrubados pela nova geração que não conheceu a perda, a dor, a mágoa e o luto de uma pátria perdida, de um solo que desconhece os seus semelhantes. Nesse aspecto, o livro revela sobremaneira a curiosidade e o ímpeto dessa nova geração que imagina e almeja o conhecimento do território perdido, que questiona a amnésia social e familiar que a rodeia e, que, secretamente, vai modulando uma outra vOz em busca de verbalizar as ausências socialmente produzidas, em busca de testemunhos que a memória dos seus familiares procurou rasurar. 
Pela personagem de Clara, representante de uma geração oriunda da diáspora cultural e identitária, a «casa-comboio» retoma o seu andamento, dirigindo-se para o passado no tempo das memórias escondidas, das histórias não ditas e não partilhadas. É tendo por referência essa personagem que se retoma a horizontalidade do tempo vivido, do tempo esquecido, refazendo, em sentido oposto ao da sua família, esse retorno às origens, a esse tique-taque não cronológico, mas subjetivo e ontologicamente marcado pela herança colonial portuguesa e indiana. Como observa Jorge Malheiros

[...] as identidades dos grupos colonizados e migrantes são "moldadas" no quadro dos processos de formação e activação dos espaços de colonização e das suas inter-ligações e, posteriormente, reconstruídas no âmbito das trajectórias de circulação migratória em contexto pós-colonial. (MALHEIROS, 2010, p. 129)

Clara, nesse sentido, espelha bem o mito do retorno, dessa vontade premente de uma percepção cíclica, porque ontológica, sobre quem somos, e o que seremos. Das indagações que emergem ao longo do questionamento sobre a sua identidade, é visível esse desencontro do eu, essa disjunção ontológica, enfim, essa procura do "modo paisagístico do seu ser" (OCHOA, 2010, p. 278), que, desse modo, suplanta as fraturas, as descontinuidades, as rupturas que o deslocamento dos seus familiares, dos Carcomo, experienciaram no tempo da pós-colonialidade portuguesa. Consequentemente, Clara refaz e reescreve o paradoxo das «identidades sem chão» (KHAN, 2006, p. 1), ao reiniciar, no sentido contrário ao de seu bisavô Honorato, que sonhava com terras alentejanas, uma viagem em torno do eu não apenas singular, mas colectivo, social, histórico e antropológico do indo-português, deixando-nos, então, um espólio de investigação que nos permite perceber que o tempo não rasura a memória, nem a nostalgia a ele ancorado - o mundo under nostalgement como também bem observou Casey (1987, p. 364). Desse modo, o tempo da pós-colonialidade, não obstante os seus vários silenciamentos, ironicamente nos diz que podemos sempre regressar, sem necessariamente permanecer. Essa transitoriedade nos lança no entendimento de que, ainda que o passado esteja adormecido e encostado em um lugar escuro e aparentemente impenetrável, ele volta sempre por meio de nossos gestos, de nossas inquietações, de nossas incertezas: 
Com a adolescência chegou o aguçar da curiosidade pela Índia, ao mesmo tempo que uma amnésia percorria toda a família, inclusivamente o avô Rudolfo. Falar da Índia e do que para trás ficara, após aqueles anos de tantas guerras perdidas, era doloroso. E não só pela tristeza de ver o país dizer adeus ao império, sobretudo para os mais velhos. Mas também porque tantos os portugueses que sempre cá estiveram como os retornados e os repatriados assumiam ser já grande a empresa de cuidarem do desenvolvimento do território continental e ilhas. Havia suficiente feridas para lamber. (OCHOA, 2010, p. 289; grifos nossos).

Mais do que uma nostalgia de um «lugar» ao qual se pertence, mas que se desconhece, Clara obriga-nos à tarefa de escavar em busca das ausências que a pós-colonialidade portuguesa foi reproduzindo, sejam sociais e políticas, sejam subjetivas, ancoradas nas vivências pós-coloniais dos seus familiares. Daí que, no quadro desta análise, seja aceitável e operacional conceber a recusa da personagem à amnésia quase geral como uma representação literária que evidencia e ilustra muito bem uma sociologia «pós-colonial» das ausências, inspirando-me na expressão de Boaventura de Sousa Santos, que metodologicamente sistematizou e denominou como sociologia das ausências (2002). O livro pressupõe a coexistência de outras experiências e de outras vozes que não aquelas que nos rodeiam, mas que servem de complemento para a compreensão desse grande cenário que é hoje o Portugal pós-colonial. A partida de Clara em direção aos lugares dessa Índia portuguesa perdida, aos espaços calcorreados pelos seus anciãos e a esse passado que a instiga, leva-a a entrar em contato com as identidades daqueles que por lá permaneceram, pois esses outros-esquecidos também trazem, indubitavelmente, para a constituição de nossa identidade, uma voz saudosista, pois como diz Clara: "Damão. Chegar à Índia e continuar a falar português, chegar à Índia e continuar a viver no meio de igrejas e paroquianos que nos perguntam pelos nossos lá da terra, esse Portugal falecido mas que continua a interessar a todos os que ficaram" (OCHOA, 2010, p. 294, grifos nossos).

Um ciclo que se fecha, ou uma viagem que, finalmente, assume o seu sentido pleno, na medida em que o império, embora «falecido», não se rasura, nem na «metrópole» pós-colonial, nem em certos espaços pós-colonizados, e a «casa-comboio» continua a viagem. 


\section{Considerações Finais: a recusa do esquecimento na pós-colonialidade portuguesa}

Chegamos ao fim de uma viagem que, no entanto, não se esgota nas páginas de vida e de identidade dos indo-portugueses que o romance de Raquel Ochoa soberbamente recuperou partindo do périplo vivencial, cultural e, porque não afirmá-lo, territorial (MUNOZ, 1994) da família Carcomo. Se o universo da escrita, como anteriormente argumentado, nos concede um tempo de leitura e de reflexão para o questionamento de como representamos hoje o real, simultaneamente, oferece-nos um espólio, ainda que num registro ficcional, das realidades socialmente periféricas na/da pós-colonialidade portuguesa. Mais do que um instrumento literário para uma aproximação entre arte e vida (DEBRAY, 1992), A casa-comboio convoca de um modo útil os silêncios e ausências de uma pós-colonialidade que relega ao esquecimento as vozes dos vencidos, daqueles que colaboraram com o colonialismo, que foram «leais» ao império português. A história do colonialismo só pode ser criticamente escrita se forem consideradas essas vozes, narrativas e memórias esquecidas (VECCHI, 2010, p. 139). A casa-comboio coloca-nos o imenso desafio de ouvirmos as razões daqueles colonizados que compartilharam com o colonialismo, que o defenderam e mesmo o promoveram. Mais difícil: coloca-nos a questão de como superarmos os preconceitos herdados do colonialismo e considerarmos como portugueses de fato, sem mácula ou distinção alguma, aqueles oriundos das colônias e todos os seus descendentes.

\section{Referências Bibliográficas}

AGUALUSA, Eduardo. Um Estranho em Goa. Lisboa: Biblioteca Editores Independentes, 2007.

ANTUNES, António Lobo. As Naus. Lisboa: Biblioteca de Bolso Edições Dom Quixote, 1990.

BUESCU, Helena. Emendar a morte. Pactos em literatura. Porto: Campo das Letras, 2008. CARDOSO, Norberto do Vale. Pós-colonialismo e discursos de resistência na Legiãa de António Lobo Antunes. In: VI Congresso Nacional Associação Portuguesa de Literatura Comparada/X Colóquio de Outono Comemorativo das Vanguardas. Braga: Universidade do Minho 2009/2010, p. 1-20. (http://ceh.ilch.uminho.pt/Pub_Norberto_Vale_Cardoso.pdf). 
CASEY, Edward S. The world of nostalgia. In: Man and World. n. 20, p. 361-384, 1987. DEBRAY, Régis. Vie et mort de l'image. Paris: Gallimard, 1992.

FERREIRA, Vergílio. Aparição. Lisboa: Livraria Bertrand, 1980.

FONSECA, Ana Margarida. Silêncios do Império - representações da identidade cultural portuguesa nas entrelinhas da descolonização. In: Dedalus, Revista Portuguesa de Literatura Comparada n. 10: 473-487, 2005.

. O meu nome é solidão: representações da pós-colonialidade na ficção de Lobo Antunes. In: VI Congresso Nacional Associação Portuguesa de Literatura Comparada/X Colóquio de Outono Comemorativo das Vanguardas. Braga: Universidade do Minho, 2009/2010. p.1-17. (http://ceh.ilch.uminho.pt/Pub_Ana_Fonseca.pdf).

GOMES, Aida. Os pretos de Pousaflores. Lisboa: Publicações Dom Quixote, 2011.

KHAN, Sheila. Identidades sem chão. Imigrantes afro-moçambicanos: narrativas de vida e de identidade, e percepções de um Portugal pós-colonial. In : Luso-Braz̧ilian Review, n. 43 (2), p. 1-26, 2006.

. Ler o "Sul" em viagem: duas epistemologias literárias do Sul global em Hinyambaan e em Um Estranho em Goa. In: Via Atlântica. São Paulo, n. 17, 2011. (no prelo).

LOURENÇO, Eduardo. O labirinto da saudade. Lisboa: Gradiva, 2001.

MALHEIROS, Jorge. Imigrantes e reconstrução identitária em contexto pós-colonial: o caso dos hindus de Lisboa e Roterdão. In: TROVÃO, Susana; ROSALES, Marta Vilar (Org.). Das Índias. Gentes, movimentos e pertenças transnacionais. Lisboa: Edições Colibri, 2010. p. 129-168.

MARTINS, Lourdes Câncio. Literatura e emigração: problemáticas da descontinuidade através da experiência ficcional contemporânea. (o caso francês). In: SERUYA, Teresa (Org.). Literatura e Migração. Lisboa: Edições Colibri, 2005. p. 81-91. . Estranhos em permanência: a negociação portuguesa na pós-colonialidade.

In: RIBEIRO, Manuela Ribeiro (Org.). Portugal não é um país pequeno. Lisboa: Edições Cotovia, 2006. p. 285-315.

OCHOA, Raquel. A Casa-Comboio. Lisboa: Gradiva, 2010.

SANTOS, Boaventura de Sousa. Para uma sociologia das ausências e uma sociologia das emergências. In: Revista Critica de Ciências Sociais. Coimbra, n. 63, p. 237-280, out., 2002.

VECCHI, Roberto. O pós-colonialismo português excepção ou excepcionalidade? In: BRUGIONI, Elena; PASSOS, Joana; SARABANDO, Andreia; SILVA, MarieManuelle (Org.). Áfricas Contemporâneas/Contemporary Africas. Famalicão: Edições Húmus, 2010. p. 129-140.

Recebido em 10/03/2011 e aprovado em 05/04/2011. 